\title{
CCN3 Impairs Osteoblast and Stimulates Osteoclast Differentiation to Favor Breast Cancer Metastasis to Bone
}

\author{
Véronique Ouellet, ${ }^{, \dagger}$ Kerstin Tiedemann, ${ }^{\neq}$ \\ Anna Mourskaia, ${ }^{, \dagger}$ Jenna E. Fong, ${ }^{\ddagger}$ \\ Danh Tran-Thanh, ${ }^{\S}$ Eitan Amir, " Mark Clemons," \\ Bernard Perbal, ${ }^{* *}$ Svetlana V. Komarova, ${ }^{\ddagger}$ and

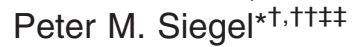 \\ From the Goodman Cancer Research Centre,* the Departments of \\ Medicine, ${ }^{\dagger}$ and Biochemistry, ${ }^{+\dagger}$ and the Faculty of Dentistry, ${ }^{\ddagger}$ \\ McGill University, Montreal, Quebec; the Department of \\ Pathology, ${ }^{\S}$ Hotel-Dieu du CHUM, Montreal, Quebec; the Division \\ of Medical Oncology, "I Princess Margaret Hospital, Toronto, \\ Ontario; the Division of Medical Oncology," Ottawa Hospital \\ Cancer Centre, Ottawa, Ontario, Canada; the Laboratoire \\ d'Oncologie Virale et Moléculaire, ${ }^{* *}$ Université Paris, Paris, \\ France; and L'Oréal, ${ }^{\#}$ Clichy, France
}

Bone is a preferred site for breast cancer metastasis, causing pain, fractures, spinal cord compressions, and hypercalcemia, all of which can significantly diminish the patient's quality of life. We identified $\mathrm{CCN} 3$ as a novel factor that is highly expressed in bone metastatic breast cancer cells from a xenograft mouse model and in bone metastatic lesions from patients with breast cancer. We demonstrate that $\mathrm{CCN} 3$ overexpression enhances the ability of weakly bone metastatic breast cancer cells to colonize and grow in the bone without altering their growth in the mammary fat pad. We further demonstrated that human recombinant $\mathrm{CCN} 3$ inhibits osteoblast differentiation from primary bone marrow cultures, leading to a higher receptor activator of NF- $\kappa B$ ligand (RANKL)/osteoprotegerin (OPG) ratio. In conjunction with its ability to impair osteoblast differentiation, we uncovered a novel role for CCN3 in promoting osteoclast differentiation from RANKI-primed monocyte precursors. $\mathrm{CCN} 3$ exerts its proosteoclastogenic effects by promoting calcium oscillations and nuclear factor of activated T cells $\mathrm{c} 1$ (NFATc1) nuclear translocation. Together, these results demonstrate that $\mathrm{CCN} 3$ regulates the differentiation of bone resident cells to create a resorptive environment that promotes the formation of osteolytic breast cancer metastases. (Am J Pathol 2011, 178:2377-2388; DOI: 10.1016/j.ajpath.2011.01.033)

Bone is the preferred site for breast cancer metastasis., ${ }^{1,2}$ Although patients with bone metastasis display better over- all survival relative to patients with visceral metastases, their quality of life can be significantly diminished due to pain, fractures, spinal cord compressions, and hypercalcemia. ${ }^{3}$ Given the pivotal role of the osteoclast in bone breakdown associated with osteolytic lesions, bisphosphonates (a class of drugs that inhibit osteoclast-dependent bone resorption) are routinely given to patients with breast cancer bone metastases. ${ }^{4}$ However, significant research efforts are now focused on the identification and development of targeted therapeutics to further enhance the management of breast cancer metastasis. ${ }^{5,6}$

The CCN family derives its name from the three founding

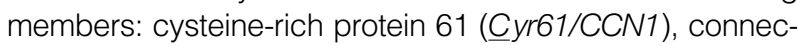
tive tissue growth factor ( $\underline{C} T G F / C C N 2)$, and nephroblastoma overexpressed (NOV/CCN3). ${ }^{7,8}$ The family also includes Wnt-inducible secreted protein-1 (WISP1/CCN4), WISP2/CCN5, and WISP3/CCN6. ${ }^{9}$ These matricellular proteins are grouped together based on the similarity of four modular domains, which include an insulin-like growth factor-binding domain, a von Willebrand factor type $\mathrm{C}$ domain (VWC), a thrombospondin type-1 repeat domain, and a cysteine-knot-containing C-terminal domain. ${ }^{10-12}$ Although

Supported by grants from the Canadian Breast Cancer Research Alliance (MOP-84386 to P.M.S.) and the Canadian Institutes for Health Research (CTP-79857 to P.M.S.). Work performed in the laboratory of B.P. was supported by European PROTHETS (Prognosis and Therapeutic Targets of Ewing Family of Tumors, FP6 contract 503036) and the French Ministry of Education. Work performed in the laboratory of S.V.K. was supported by the Canadian Institutes for Health Research (MOP-77643). Supported by a fellowship (V.O.) and a studentship (A.M.) from the Fonds de la recherche en santé du Québec and the Canadian Institutes for Health Research Training Program in Skeletal Health Research and McGill University (J.E.F.). S.V.K. holds a Canada Research Chair in Osteoclast Biology, M.C. and E.A. acknowledge support from the family of the late Judith Burstein, and P.M.S. acknowledges support from the Canadian Cancer Society and the Fonds de la recherche en santé du Québec.

Accepted for publication January 13, 2011.

None of the authors disclosed any relevant financial relationships.

Supplemental material for this article can be found at http://ajp. amjpathol.org or at doi: 10.1016/j.ajpath.2011.01.033.

Current address of B.P., L'Oréal S.A. Recherche et Innovation, Clichy, France.

Address reprint requests to Peter M. Siegel, Ph.D., Rosalind and Morris Goodman Cancer Research Centre, McGill University, 1160 Pine Ave. W., Room 513, Montreal, Canada H3A 1A3. E-mail: peter.siegel@mcgill.ca. 
the CCN proteins were originally identified as growth factors themselves, they are now thought to modify mitogenic responses by virtue of their ability to interact with and modulate the function of growth factors and cell surface receptors. ${ }^{11,12}$

CCN3 exerts diverse and dichotomous functions in cancer cells. Whereas some studies suggest that CCN3 exerts growth suppressive effects on glioma, melanoma, and breast cancer cells, ${ }^{13-15}$ others support a prometastatic role for this protein in melanoma. ${ }^{16}$ CCN3 can impair the proliferation of Ewing's sarcoma cells but promote their migration and invasion, ${ }^{17}$ supporting the observed association between high CCN3 levels and metastatic disease in this cancer type. ${ }^{18,19}$ Finally, high CCN3 levels correlate with poor outcome in patients with osteosarcoma or prostate cancer. ${ }^{20,21}$ Together, these studies demonstrate that the effects of CCN3 are context dependent; however, the role of $\mathrm{CCN} 3$ in breast cancer progression to metastasis remains unclear.

We previously used $4 \mathrm{~T} 1$ murine breast cancer cells to isolate subpopulations with enhanced bone metastasis ability. ${ }^{22}$ Using this system, we identified targets relevant to breast cancer progression and bone metastasis. ${ }^{22,23}$ We now describe the identification of three members of the CCN family as differentially expressed in weakly versus aggressively bone metastatic breast cancer cells. The present results indicate that CCN3 functions to promote the formation of osteolytic breast cancer metastases by modulating the bone microenvironment to favor osteoclast differentiation.

\section{Materials and Methods}

\section{DNA Constructs}

A pCMV82 vector ${ }^{24}$ containing the full-length human CCN3 cDNA (GeneBank Accession number X96584) was kindly provided by Dr. Laure Rittié (University of Michigan, Ann Arbor, MI). PCR was performed using the following primers: CCN3, 5'-TGGATCCACCATGCAGAGTGTGCAGAG-3' (sense) and 5'-GGAATTCTTACATाTCCCTCTGGTAG-3' (antisense), and the PCR product was digested with EcoRl and BamHI and ligated into the EcoRI and Bglll sites of pMSCVpuro vector (Clontech Laboratories, Mountain View, CA). Viruses were packaged in 293 vesicular stomatitis virus cells (kindly provided by Dr. Alain Nepveu, McGill University, Montreal, Canada), and 66cl4 cells were infected and selected to generate stable populations expressing human $C C N 3$. Stable cell lines were maintained under 4 $\mu \mathrm{g} / \mathrm{mL}$ puromycin antibiotic selection.

\section{Cell Culture}

The $66 \mathrm{cl} 4$ murine mammary carcinoma cell lines were obtained from American Type Culture Collection (Rockville, MD). Cell lines were grown in Dulbecco's modified Eagle's medium (DMEM) supplemented with $10 \%$ fetal bovine serum, $10 \mathrm{mmol} / \mathrm{L}$ HEPES, $1 \mathrm{mmol} / \mathrm{L}$ sodium pyruvate, and $1.5 \mathrm{~g} / \mathrm{L}$ sodium bicarbonate. The RAW 264.7 murine monocytic cell line was also obtained from American Type Culture Collection and grown in DMEM supplemented with $10 \%$ fetal bovine serum, $1.5 \mathrm{~g} / \mathrm{L}$ sodium bicarbonate, $4.5 \mathrm{~g} / \mathrm{L}$ glucose, and $1 \%$ sodium pyruvate (Wisent Inc., St-Bruno, Canada).

\section{Microarray Analysis}

Agilent gene expression data previously generated in our laboratory ${ }^{22}$ was subjected to additional analysis (parametric test, $5 \%$ false discovery rate) using GeneSpring (Agilent, Santa Clara, CA) comparing the 4T1 parental cell line with bone metastatic subpopulations (590, 592, and 593). Differentially expressed genes were identified using a parametric test combined with a false discovery rate of 0.05. ccn1, ccn2, and ccn3 expression, derived from the Agilent data, is shown in Supplemental Figure S1 (available at http://ajp.amjpathol.org).

\section{RNA Extraction, cDNA Synthesis, and Quantitative PCR}

RNA extraction and cDNA synthesis were performed as previously described. ${ }^{22}$ Labeling was performed using SYBR Green PCR Master Mix (Hoffmann-La Roche Ltd., Mississauga, Canada) in a final volume of $25 \mu \mathrm{L}$, which contained $5 \mu \mathrm{L}$ of diluted CDNA template and $10 \mathrm{pg}$ of the necessary primers. PCR reactions were performed as described by the manufacturer. The following primers were used for PCR amplification: for con1, 5'-GAAAAGGCAGCTCACTGAAG-3' (sense) and 5'-GGGTTGTCATTGGTAACTCG-3' (antisense); for ccn2, 5'-AGCTGGGAGAACTGTGTACG-3' (sense) and 5'-TTGGTATTTGCAGCTGCTTT-3' (antisense); for ccn3, 5'-AGACTCGTCTCTGCATCGTT-3' (sense) and 5'-CTCGAACTGTAGGTGGATGG-3' (antisense); and for glycer aldehyde-3-phosphate dehydrogenase (Gapdh), 5'-CAAGTATGATGACATCAAGAAGGTGG-3' (sense) and 5'-GGAAGAGTGGGAGTTGCTGTTG-3' (antisense). Experiments were performed in triplicate using three different cDNA preparations. Quantification of gene expression was performed using the Pfaffl analysis method. ${ }^{25}$ In each experiment, the 4T1 sample served as the reference sample and Gapdh was used as the control. For gene expression analysis from primary cell cultures, we used the TaqMan Universal PCR Master Mix (Applied Biosystems, Streetsville, Canada) and the following TaqMan gene expression assays: $\beta$-actin (Mm00607939_s1), RANKL (Mm00441908_m1), and Opg (Mm01205928_ m1). The $\Delta \Delta \mathrm{Ct}$ method was used to obtain the expression ratio using bovine serum albumin (BSA) as the control. Real-time PCR was performed using an Applied Biosystems 7500 instrument (Applied Biosystems).

\section{Immunoblotting}

Cells were grown to $80 \%$ confluence and were lysed in TNE lysis buffer as previously described. ${ }^{26}$ Unless otherwise indicated, $30 \mu \mathrm{g}$ of total protein or $30 \mu \mathrm{L}$ of conditioned media was loaded on $10 \%$ to $12 \%$ SDS-polyacrylamide gels and was transferred to polyvinylidene difluoride membranes. Membranes were blocked in 5\% milk-Tris-buffered saline Tween-20 and were incubated 
overnight at $4^{\circ} \mathrm{C}$ with the appropriate primary antibodies. Antibodies specific to CCN1 (N19; 1:800 dilution), CCN2 (K28T; 1:800 dilution), and CCN3 (K19M; 1:1500 dilution) have been described previously, $24,27,28$ and the $\alpha$-tubulin antibody was purchased from Sigma-Aldrich (St. Louis, MO) (1:10,000 dilution; catalog number T6199).

Activation of cell signaling pathways was assessed by first plating $5 \times 10^{4}$ RAW 264.7 cells into individual wells of a six-well plate. Cells were primed for 48 hours with 50 $\mathrm{ng} / \mathrm{mL}$ receptor activator of NF- $\kappa \mathrm{B}$ ligand (RANKL) and subsequently were stimulated for 15,30 , or 60 minutes with DMEM alone or DMEM containing either $50 \mathrm{ng} / \mathrm{mL}$ of mouse recombinant RANKL (rRANKL) resuspended in 0.1\% BSA (catalog number 315-11; Peprotech, Rocky Hill, NJ) or 600 $\mathrm{ng} / \mathrm{mL}$ of human recombinant CCN3 ( $\mathrm{rCCN} 3$ ) resuspended in $0.1 \%$ BSA (catalog number 120-26; Peprotech). CCN3 cells were washed twice in PBS, and protein lysates were extracted using radioimmunoprecipitation assay buffer as previously described. ${ }^{29}$ Membranes were blocked in 5\% BSA-Tris-buffered saline Tween-20 and were incubated with ERK (1:1000 dilution; catalog number 9102), p-ERK (1:1000 dilution; catalog number 9101), JNK (1:1000 dilution; catalog number 9252), p-JNK (1:1000 dilution; catalog number 9251), PKC $\alpha$ (1:1000 dilution; catalog number 2056), or $\mathrm{p}-\mathrm{PKC} \alpha / \beta$ (1:1000 dilution; catalog number 9375) antibodies, all of which were purchased from Cell Signaling Technology (Danvers, MA).

The appropriate horseradish peroxidase-conjugated anti-rabbit secondary antibodies (catalog number 711 035-152; Jackson ImmunoResearch Laboratories, West Grove, PA) were used at a dilution of 1:5000, and membranes were visualized using an enhanced chemiluminescence system (catalog number 34080; Pierce Biotechnology, Nepean, Canada).

\section{ELISA}

To generate the conditioned media, cells were plated in $100-\mathrm{mm}$ dishes in complete medium. The following day, the medium was replaced with $5 \mathrm{~mL}$ of serum-free medium and was allowed to condition for 48 hours. We used the mouse nov/ccn3 DuoSet (catalog number DY1976; R\&D Systems, Minneapolis, MN) enzyme-linked immunosorbent assay (ELISA) kit to detect ccn3 in the conditioned medium harvested from the 4T1 derivatives and the human NOV/CCN3 DuoSet (catalog number DY1640; R\&D Systems) ELISA kit from $66 \mathrm{cl} 4$ cells engineered to express human $\mathrm{CCN} 3$. Conditioned media was diluted (1:2 for 4T1 derivatives and 1:10 for $66 \mathrm{cl} 4$ cells) into the reagent diluent concentrate 2 (catalog number DY995; R\&D Systems). Experiments were performed in duplicate on two independent harvests of conditioned media from 66cl4 cells and 4T1 derivative populations. Data are expressed as picograms per milliliter of CCN3 per microgram of total protein per 48 hours.

\section{Immunohistochemical Analysis}

FFPE blocks of bone metastatic lesions were obtained from patients with breast cancer who had previously undergone orthopedic surgery at Mount Sinai Hospital (Toronto, Canada) for pathologic fractures. Immunostaining was per- formed using a polyclonal rabbit anti-CCN3 antibody (K19M antibody; 1:400 dilution). The staining intensity was evaluated by two different observers (including one pathologist, D.T.-T.), incorporating the percentage positivity and strength (negative, weak, moderate, and strong) of the observed staining. Local research ethics board (Mount Sinai Hospital) approval was obtained for the tissue banking and testing of samples used in this study.

\section{In Vitro Proliferation and in Vivo Tumorigenesis/ Metastasis Assays}

Cell proliferation assays were performed by plating $8 \times$ $10^{3}$ cells from infected pools of $66 \mathrm{cl} 4$ cells harboring an empty vector $(\mathrm{VC})$ or overexpressing human $\mathrm{CCN} 3$ into 12-well plates. Cells were counted every day for 4 days using an automated cell counter (Cellometer; Nexcelom Bioscience, Lawrence, MA). Two independent experiments were performed, and triplicate wells were counted at each time point.

To assess tumor growth in vivo, $66 \mathrm{cl} 4$ mammary carcinoma cells were harvested from subconfluent plates and were washed once with PBS, and $1 \times 10^{5}$ cells were resuspended in $50 \mu \mathrm{L}$ of a $50: 50$ solution of Matrigel (BD Biosciences, Mississauga, Canada) and PBS. Cell suspensions were injected into the right and left abdominal mammary fat pads of BALB/c mice ( $n=5$ per group) (Charles River Laboratories, St-Constant, Canada), and weekly tumor measurements were obtained. Tumor volumes were calculated using the following formula: $\pi L W 2 / 6$, where $L$ is the length and $W$ is the width of the tumor.

To evaluate the capacity of the cells to form bone metastases, we injected the $66 \mathrm{cl} 4$ mammary carcinoma cells $\left(10^{5}\right.$ cells) into the left cardiac ventricle of 4- to 5-week-old BALB/c mice as previously described. ${ }^{22}$ To visualize bone metastases, mice were anesthetized, and digital X-rays were taken using an XPERT80 specimen radiography system (KUB Technologies, Milford, CT) on day 7 after injection and before sacrifice (day 14). Paraformaldehyde-fixed tissues were paraffin embedded, sectioned, and subjected to H\&E staining. The number of mice possessing at least one histologically verified lesion was divided by the total number of animals in each cohort to determine the percentage of mice developing bone metastases. The number of lesions over the total number of bones (femur and tibia) analyzed in each cohort was also determined. To quantify lesion area/ bone area, a distance of $5 \mathrm{~mm}$ was measured from the head of the femur or tibia (at the joint) down the shaft of the bone. The area of this region of bone was calculated by tracing the outline of the femur or tibia, ending at the 5-mm point, using ImageScope (Aperio Technologies, Vista, CA). This allowed a standard tissue area to be calculated across all samples. For bones possessing a lesion, the area of the metastases was circumscribed and quantified using a positive pixel count algorithm (ImageScope). The percentage of lesion area/bone area was then calculated. 


\section{Osteoblast Differentiation Assay}

Mouse-derived bone marrow cells were collected from mouse tibia and femora as described previously. ${ }^{29}$ One day after plating, $50 \mathrm{ng} / \mathrm{mL}$ ascorbic acid (AA) (A5960; SigmaAldrich Canada Ltd, Oakville, ON, Canada) was added to induce osteoblast differentiation. The indicated treatments, including 600 ng/mL BSA (BioShop Canada Inc., Burlington, Canada) and $600 \mathrm{ng} / \mathrm{mL}$ rCCN3 (Peprotech) were freshly added on days $1,3,5$, and 7 . On day 9 , cell cultures were fixed using 4\% paraformaldehyde for 10 minutes, washed with PBS, and stained for alkaline phosphatase (Fast Red, catalog number F4381; Sigma-Aldrich). Images were analyzed using BIOQUANT software (BIOQUANT Image Analysis Corp, Nashville, TN) and are expressed as the average percentage coverage over the well.

\section{Osteoclast Differentiation Assay}

Osteoclast differentiation assays were performed as previously described. ${ }^{30}$ Briefly, $5 \times 10^{3}$ RAW 264.7 cells were plated in each well of a 48-well plate. On day 1 and day 3 , fresh media containing the specified factors was applied to the cultures (rRANKL, $50 \mathrm{ng} / \mathrm{mL}$; rCCN3, 600 $\mathrm{ng} / \mathrm{mL}$ ). When specified, cells were incubated with $\mathrm{Ca}^{2+}$ chelator BAPTA-acetoxymethyl ester (catalog number B-6769; Invitrogen, Carlsbad, CA) on day 3 for 10 minutes and were washed before treatment with recombinant protein as previously described. ${ }^{31}$ Cells were fixed in $4 \%$ paraformaldehyde and were stained for tartrateresistant acid phosphatase (catalog number 387A; Sigma-Aldrich).

\section{Microspectrofluorometry}

$\mathrm{Ca}^{2+}$ imaging was performed as previously described. ${ }^{30}$ Raw 264.7 cells were plated on glass-bottom 35-mm dishes (MatTek Corp., Ashland, MA). rRANKL-primed cells were washed twice and loaded at room temperature for 40 minutes with fura-2-AM (catalog number F1221; Invitrogen). $\left[\mathrm{Ca}^{2+}\right]_{\mathrm{i}}$ was calculated using a fura-2 calcium imaging calibration kit (catalog number F-6774; Invitrogen). After recording a baseline DMEM, $50 \mathrm{ng} / \mathrm{mL}$ rRANKL or $600 \mathrm{ng} / \mathrm{mL}$ rCCN3 was added to the plate and the calcium concentration was recorded for $120 \mathrm{sec}-$ onds. A cell was considered as oscillating when two or more peaks were recorded.

\section{Immunofluorescence}

To examine ccn3 localization or nuclear factor of activated T cells c1 (nfatc1) nuclear translocation, cells were plated onto glass coverslips that were placed on the bottom of a 24-well dish. ccn3 immunofluorescence was performed as previously described ${ }^{31}$ using an Alexa488-conjugated goat anti-rabbit antibody (catalog number A11034; Invitrogen). For nfatc1 immunofluorescence, RAW cells that were left unprimed or primed for 48 hours with $50 \mathrm{ng} / \mathrm{mL} \mathrm{rRANKL}$ were stimulated with DMEM alone or DMEM containing either rRANKL ( $50 \mathrm{ng} / \mathrm{mL}$ ) or rCCN3 (600 ng/mL) for 15, 30, and 60 minutes. nfatc 1 immuno- fluorescence was performed as previously described ${ }^{32}$ using a mouse anti-nfatc1 antibody (catalog number 7294; Santa Cruz Biotechnology, Santa Cruz, CA) and Alexa-488-conjugated goat anti-mouse antibody (catalog number A11029; Invitrogen). Four to eight random fields were quantified for each condition. Cells were considered positive for nfatc1 nuclear localization if the fluorescence intensity of nuclei exceeded that of cytoplasm.

\section{Statistical Analysis}

Statistical analyses (parametric t-test) were performed using VassarStats software (http://faculty.vassar.edu/ lowry/VassarStats.htm/). $P<0.05$ was considered significant.

\section{Results}

\section{CCN3 Expression Is Higher in Bone Metastatic Breast Cancer Cell Populations}

We previously described the isolation of $4 \mathrm{~T} 1$ breast cancer cells that are aggressively metastatic to the bone. ${ }^{22}$ Additional analysis of differentially expressed genes in weakly (4T1 and 511) versus aggressively (590, 592, and 593) bone metastatic breast cancer cells identified three members of the CCN family: ccn1, ccn2, and ccn3. Agilent microarray data revealed that $c c n 1$ and ccn2 transcript levels are higher in weakly bone metastatic populations, whereas ccn3 is overexpressed in breast cancer cells that aggressively metastasize to bone (see Supplemental Figure S1A at http://ajp.amjpathol.org). Quantitative PCR analyses confirmed that ccn1 and ccn2 transcripts were, indeed, reduced and that ccn3 mRNA was elevated in aggressively bone metastatic breast cancer cells compared with their weakly bone metastatic counterparts (Figure 1A). Finally, we performed immunoblot analyses on whole-cell lysates and conditioned media from the 4T1-derived subpopulations. Whereas ccn1 expression was reduced in the aggressively bone metastatic populations compared with in the weakly bone metastatic cells, ccn2 levels were similar across all subpopulations examined (see Supplemental Figure S1, B and C, at http://ajp.amjpathol.org). Neither CCN1 nor CCN2 was found in the conditioned media of the cells (data not shown). In contrast, a higher level of secreted CCN3 was observed in the aggressively bone metastatic populations compared with their weakly metastatic counterparts. This corresponded with a concomitant reduction in ccn3 expression levels in whole-cell lysates from aggressively bone metastatic breast cancer populations (Figure 1B). We further quantified the amount of secreted ccn3 in conditioned media of aggressively and weakly bone metastatic cells by ELISA. On average, the aggressively metastatic breast 4T1derived cancer cells secreted approximately twice the amount of ccn3 compared with the weakly bone metastatic cells (Figure 1C). Finally, we performed immunofluorescence staining to determine whether ccn3 localization varied between the in vivo selected versus 

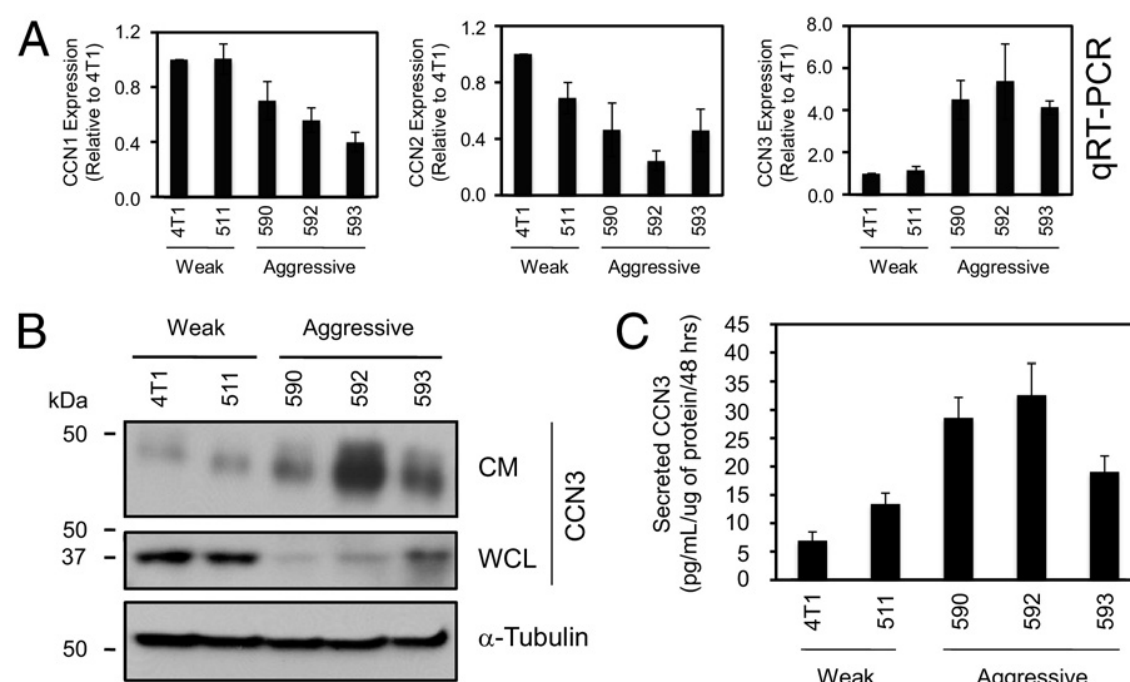

\begin{abstract}
Figure 1. con 3 expression is elevated in highly bone metastatic 4T1 populations. A: ccn1 (left) $\operatorname{ccn} 2$ (middle), and con3 (right) mRNA expression normalized to gapdh and expressed relative to $4 \mathrm{~T} 1$ parental cells was determined using quantitative real-time PCR (qRT-PCR). The data are representative of three independent experiments, each performed in triplicate. B: Immunoblot analysis of $\mathrm{ccn} 3$ protein expression in the conditioned media (CM; top) or whole-cell lysate (WCL; middle) of weakly (4T1 and 511) and highly $(590,592$, and 593) bone metastatic cell populations. An immunoblot for $\alpha$-tubulin (bottom) served as loading control. C: The concentration of secreted con3 protein in CM was determined by ELISA. Error bars represent SD.
\end{abstract}

parental cell populations. We observed the accumulation of ccn3 in cellular protrusions specifically in the highly bone metastatic subpopulations (592) compared with parental 4T1 cells (see Supplemental Figure $\mathrm{S} 2$ at $h$ ttp://ajp.amjpathol.org). This observation is in agreement with previously published data demonstrating that CCN3 overexpressed in MDA-MB-231 cells also localizes to the leading edge of actin-rich cellular protrusions. ${ }^{33}$ Together, these results demonstrate that CCN3 is highly expressed in bone metastatic breast cancer cells and raises the possibility that it may play a functional role in this process.

\section{CCN3 Is Expressed in Bone Metastases from Patients with Breast Cancer}

To extend these observations from a murine model of breast cancer bone metastasis to the human disease, we performed immunohistochemical staining for $\mathrm{CCN} 3$ on paraffin-embedded bone metastatic lesions from human patients with breast cancer. Most of these samples were characterized as luminal tumors based on estrogen receptor/progesterone receptor positivity (see Supplemental Table S1 at $h t t p: / / a j p . a m j p a t h o l . o r g)$. Staining intensity and the extent of positivity were scored, and we found that of the 14 bone metastasis samples available for analysis, half possess moderate to strong staining in most of the tumor epithelium (Figure 2). However, moderate to strong CCN3 expression in the stromal compartment was present in most of the bone metastases analyzed (11 of 14) (Figure 2). These results demonstrate that strong CCN3 expression in the tumor epithelium or stroma is a common feature of human breast cancer bone metastases.

\section{CCN3 Overexpression Increases Bone Metastasis}

To investigate a role for $\mathrm{CCN} 3$ in promoting breast cancer metastasis to bone, we used the $66 \mathrm{cl} 4$ breast cancer cell line, which was derived from the same primary tumor as $4 \mathrm{~T} 1$ cells but lacks robust bone metastatic ability. ${ }^{34,35} \mathrm{We}$ infected $66 \mathrm{cl} 4$ cells with virus carrying a VC or an expression vector containing the full-length human CCN3 CDNA. The CCN3-infected pool displayed elevated levels of CCN3 in whole-cell lysates and conditioned media compared with 66cl4 VC control cells (Figure $3, \mathrm{~A}$ and B). Previous studies have demonstrated that $\mathrm{CCN} 3$ can either enhance or reduce the growth of various cell types. ${ }^{12}$ To investigate this possibility in the present system, we established in vitro growth curves for VC control and CCN3-expressing 66 $\mathrm{cl} 4$ cells and found that CCN3 expression has little effect on the growth of these breast cancer cells (Figure 3C). We extended these analyses in vivo and determined that $\mathrm{CCN} 3$ expression did not affect the tumor formation or outgrowth of $66 \mathrm{cl} 4$ cells in BALB/c mice (Figure 3D).

We next determined whether CCN3 could affect the ability of breast cancer cells to form osteolytic bone metastases. VC control and CCN3-expressing 66cl4 cells were injected into the left cardiac ventricle, and mice were sacrificed 14 days later. Hind limb sections were H\&E stained and examined for the presence of bone metastases. We found that $14 \%$ of mice (2 of 14 ) injected with 66cl4-VC control cells developed metastases compared with $31 \%$ of animals (4 of 13 ) injected with CCN3-expressing cells (Figure 4A, left). Moreover, when the number of lesions per bone (femur or tibia) was scored, we observed that $4 \%$ of bones ( 2 of 56 ) contained $66 \mathrm{cl} 4-\mathrm{VC}$-derived lesions compared with $17 \%$ of bones (9 of 52) with 66cl4CCN3-expressing lesions ( $P=0.025$; Figure 4A, middle). We next quantified the total tumor burden in bone lesions formed by VC control and CCN3-expressing breast cancer cells. We observed that the average percentage of tumor area/tissue area in lesions formed from control cells was 1.7 times smaller than that in lesions arising from CCN3-expressing cells [Figure 4, A (right) and B]. These results demonstrate that $C C N 3$ specifically enhances the formation of bone metastases without affecting mammary tumor outgrowth in the primary site. 
A

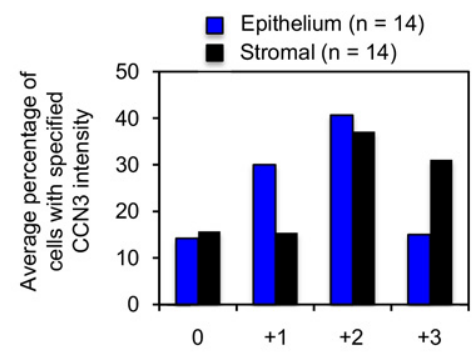

B
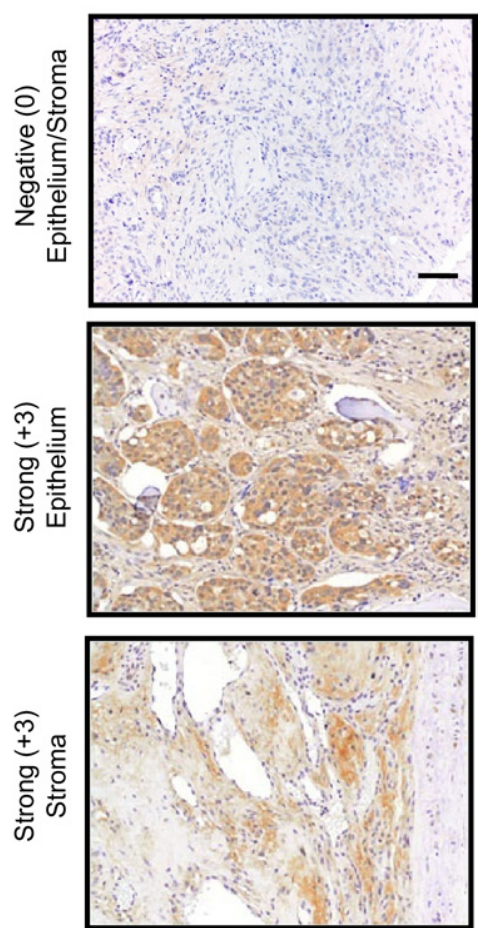

Figure 2. $\mathrm{CCN} 3$ is expressed in human bone metastatic lesions from patients with breast cancer. A: Quantification of CCN3 staining in epithelial (blue) and stromal (black) compartments of breast cancer bone metastases. B: Representative images of human bone metastatic lesions from patients with breast cancer with negative epithelial and stromal CCN3 staining (top), strong epithelial CCN3 staining (middle), and strong stromal CCN3 staining (bottom). Scale bar $=2 \mu \mathrm{m}$

\section{CCN3 Inhibits Osteoblast Differentiation and Promotes Osteoclastogenesis in rRANKL-Primed Precursors}

Breast cancer cells must interact productively with bone resident cells, such as osteoblasts and osteoclasts, to establish metastases in the bone. ${ }^{6,36}$ Recently, a role for ccn3 as an inhibitor of osteoblast differentiation has been revealed. ${ }^{37-40}$ To confirm this, we established an in vitro osteoblast differentiation assay using primary cultures of bone marrow cells. Ascorbic acid was used as an inducer of osteoblast differentiation, which was measured by the degree of alkaline phosphatase staining (Figure 5A). Human rCCN3 impaired ascorbic acid-induced osteoblast differentiation from murine primary bone marrow cells in a dose-dependent manner, causing a 19\% decrease in alkaline phosphatase staining at a concentration of 300 $\mathrm{ng} / \mathrm{mL}(P=0.05)$ and a $44 \%$ decrease at $600 \mathrm{ng} / \mathrm{mL}$
$(P=0.001)$. Thus, CCN3 is a potent inhibitor of osteoblast differentiation.

The RANKL/osteoprotegerin (OPG) system is critical for modulating the cross talk between osteoblasts and osteoclasts. ${ }^{41-43}$ It is known that RANKL expression is highest in osteoblast precursors and diminishes during osteoblast differentiation. Conversely, OPG levels are low in osteoblast precursors and its expression increases as osteoblasts differentiate. ${ }^{44}$ To determine whether CCN3 influences the levels of RANKL and OPG during osteoblast differentiation, we examined their expression in ascorbic acid-treated primary bone marrow cultures that were cultured in the absence or presence of $600 \mathrm{ng} / \mathrm{mL} \mathrm{rCCN} 3$. We demonstrate that rCCN3-treated cells expressed higher levels of RANKL and lower levels of OPG compared with untreated control cultures (Figure 5B, top). The increased RANKL/ OPG ratio (Figure 5B, bottom) induced by $\mathrm{rCCN} 3$ is presumably mediated through an indirect effect on osteoblast differentiation.

Although these observations suggest that CCN3 could indirectly influence osteoclast formation through impaired osteoblast differentiation, we asked whether CCN3 might have a direct role in modulating osteoclast differentiation. To address this question, we used RAW 264.7 cells, a mouse monocytic cell line that expresses macrophage colony-stimulating factor and its receptor and can differentiate into osteoclast-like cells after treatment with rRANKL. ${ }^{45,46}$ First, we assessed whether addition of rCCN3 could substitute for rRANKL to induce osteoclast formation from monocytes. However, we did not observe
A

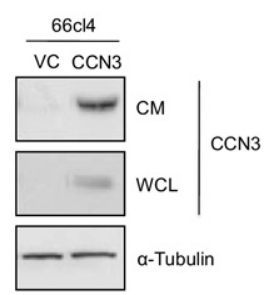

C

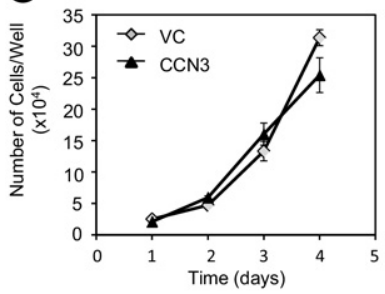

B

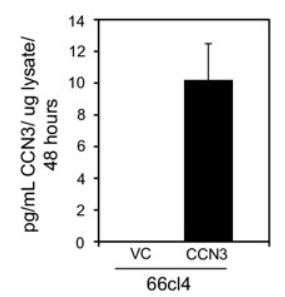

D

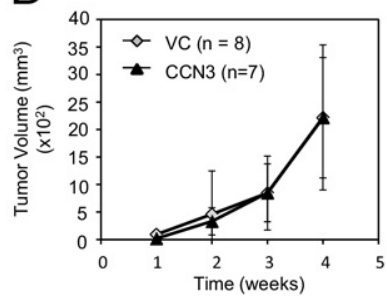

Figure 3. CCN3 overexpression does not promote mammary tumorigenesis. A: Immunoblot of CCN3 expression in the conditioned media (CM) and whole-cell lysate (WCL) of $66 \mathrm{cl} 4$ cells harboring a VC or an infected pool engineered to overexpress human CCN3. An immunoblot for $\alpha$-tubulin serves as loading control. B: Secreted CCN3 protein in the CM was quantified by ELISA. Concentrations are expressed as picograms per milliliter of CCN3 present in media conditioned for 48 hours that has been normalized to micrograms of total lysate. C: In vitro proliferation assays for $66 \mathrm{cl} 4$ cells harboring a VC and an infected pool overexpressing human CCN3. Data are representative of two independent experiments, counted in triplicate for each time point. D: In vivo mammary outgrowth for $66 \mathrm{cl} 4$ cells overexpressing human $C C N 3$ compared with $\mathrm{VC}$ control cells. The average tumor volume was calculated from eight individual VC and seven independent CCN3overexpressing mammary tumors. Error bars represent SD. 

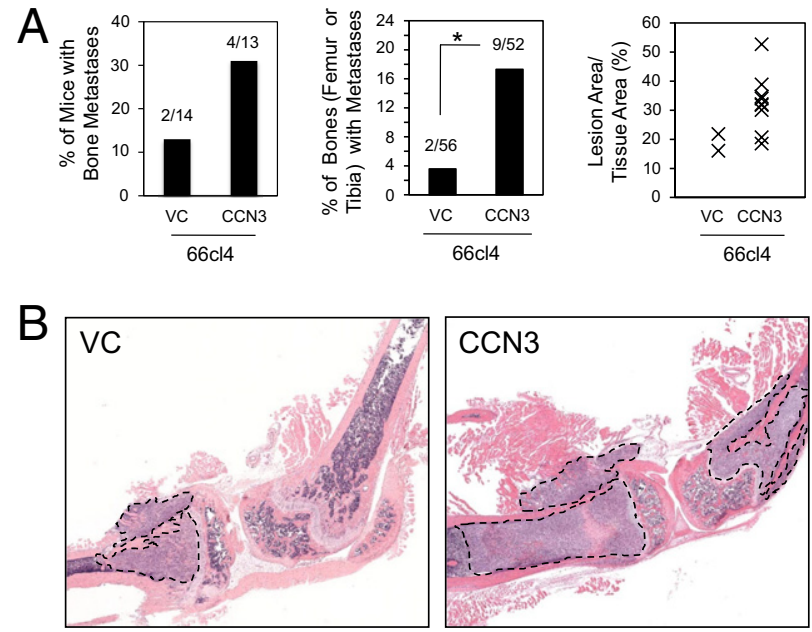

Figure 4. CCN3 expression enhances the formation of bone metastases. A: Cardiac injections were performed with $66 \mathrm{cl} 4$ cells harboring a VC or those overexpressing human CCN3. Mice were sacrificed after 2 weeks, and the percentage of mice developing histologically verified lesions (left), the percentage of bones (femur or tibia) possessing lesions (middle), and the percentage tumor area/tissue area (right) were determined. ${ }^{*} P=0.025$. B: Representative images of H\&E-stained hind limbs are shown from mice injected with VC (left) or CCN3-expressing 66 $\mathrm{cl} 4$ (right). Dotted lines delimit the region of hind limbs with 66cl4-derived bone metastatic lesions.

osteoclast formation in cultures treated only with rCCN3 (see Supplemental Figure S3, CC, at http://ajp.amjpathol.org), which resembled the undifferentiated monocytes present in RAW 264.7 cells cultured in DMEM alone (see Supplemental Figure S3, DD, at http://ajp.amjpathol.org). We previously showed that soluble factors produced by breast cancer cells can induce osteoclast formation from monocytes primed for a short time with $\operatorname{rRANKL}^{30,32}$; therefore, we considered whether rCCN3 could be effec- tive in inducing osteoclastogenesis from rRANKL-primed precursors. RAW 264.7 cells were primed for 2 days with rRANKL, after which the media was replaced by DMEM alone or DMEM containing rCCN3 (600 ng/mL). We observed the cultures for an additional 2 days and stained them for tartrate-resistant alkaline phosphatase, a marker of osteoclast differentiation. We found that rCCN3 induced an eightfold increase in the number of osteoclasts that formed in rRANKL-primed cultures compared with rRANKL-primed cells treated with DMEM (Figure 5, C and D). In addition, rRANKL-primed cells (2 days) subsequently treated with a combination of $r R A N K L$ and rCCN3 (3 days; see Supplemental Figure S3, RR + C, at http://ajp.amjpathol.org) repeatedly displayed higher numbers of osteoclasts compared with cultures subjected to 5 days of rRANKL treatment (see Supplemental Figure S3, RR, at http://ajp.amjpathol.org); however, this trend was not significant. This is the first evidence that CCN3 can directly enhance the differentiation of osteoclast precursors that have been primed with rRANKL.

\section{CCN3 Induces Intracellular Calcium Oscillations in rRANKL-Primed RAW 264.7 Cells}

Based on these results, we investigated how CCN3 could potentiate osteoclast differentiation in RANKLprimed precursors. Previous studies demonstrated that CCN3 could induce intracellular calcium release and the uptake of extracellular calcium in glioblastoma cells. ${ }^{47,48}$ Moreover, it has been demonstrated that $\mathrm{Ca}^{2+}$ signaling is critical for osteoclast differentiation. ${ }^{49}$ Based on these observations, we evaluated whether CCN3 could influence $\left[\mathrm{Ca}^{2+}\right]_{i}$ in rRANKLprimed RAW 264.7 cells. RAW 264.7 cells were primed for 48 hours with rRANKL, and the cells were subse-
A

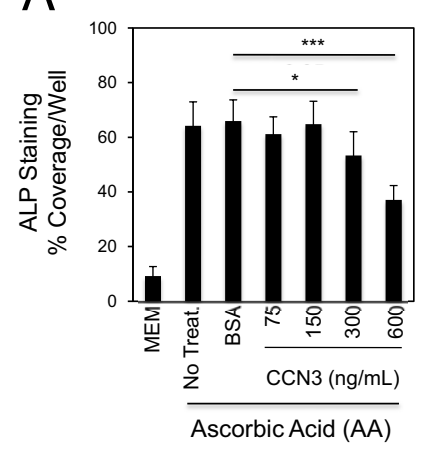

C

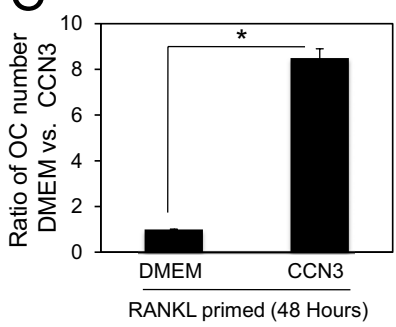

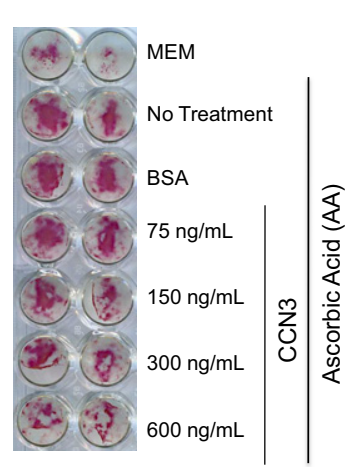
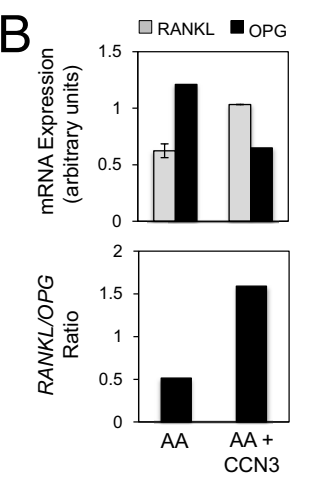

D

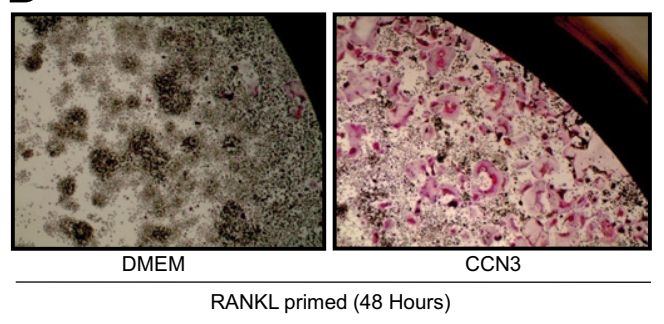

Figure 5. $\mathrm{CCN} 3$ impairs osteoblast differentiation while stimulating osteoclast differentiation. A: Ascorbic acid (AA)-induced osteoblast differentiation from primary bone marrow cultures was quantified after treatment with BSA or rCCN3 by measuring the average surface area of alkaline phosphatase (ALP) staining (left). MEM indicates cultures that were not stimulated with AA. Data are the average of six independent experiments performed in duplicate. Error bars represen SE. ${ }^{*} P=0.05,{ }^{* * * *} P \leq 0.001$. Representative image depicting ALP staining of primary mouse bone marrow cells in response to the indicated treatments (right). B: Quantitative RT-PCR was performed to monitor expression of RANKL and OPG mRNA (normalized to $\beta$-actin) in primary bone marrow cells after 9 days of treatment with AA alone or combined with $600 \mathrm{ng} / \mathrm{mL}$ rCCN3 (top). Ratio of RANKL/OPG expression in AAand rCCN3-treated primary bone marrow cultures (bottom). Data represent the average of three independent experiments performed in triplicate. Error bar represents SE. C: Osteoclast numbers observed in rRANKL-primed cultures treated with rCCN3 (600 ng/ $\mathrm{mL}$ ) were normalized to the numbers observed in rRANKL-primed cultures treated with DMEM. Data are the average of four independent experiments performed in duplicate. Error bars represent SE. ${ }^{*} P<$ 0.001 . D: Representative images of tartrate-resistant alkaline phosphatase-stained RAW 267.4 mouse monocytic cells primed with $50 \mathrm{ng} / \mathrm{mL}$ rRANKL for 48 hours followed by addition of DMEM alone (left) or DMEM containing human rCCN3 $(600 \mathrm{ng} / \mathrm{mL})$ (right) for 48 hours. 

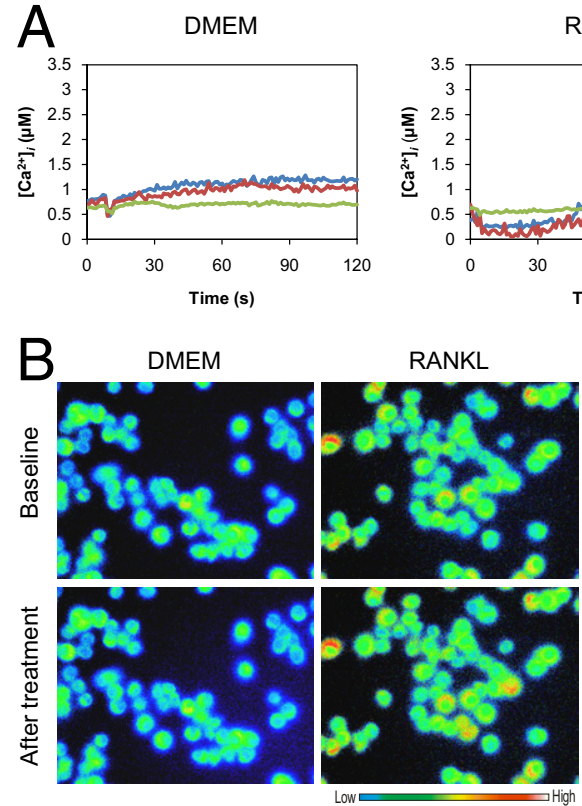

[Cal $]_{\text {ind }}^{2}$

quently loaded with fura-2-AM. The $\left[\mathrm{Ca}^{2+}\right]$; was measured over 2 minutes after addition of DMEM, rRANKL (50 ng/mL), or rCCN3 (600 ng/mL). Cells were considered as oscillating when at least two peaks of calcium increase were observed during the recording time. As expected, DMEM addition [Figure 6, A and B (left)] induced no changes in $\left[\mathrm{Ca}^{2+}\right]_{i}$, whereas rRANKL-stimulated cells [Figure 6, A and B (middle)] displayed calcium oscillations. We found that rCCN3 treatment of RAW 264.7 cells also induced rapid oscillatory changes in $\left[\mathrm{Ca}^{2+}\right]_{i}$ [Figure 6, A and B (right)]. Moreover, the percentage of cells in a field undergoing active oscillations in $\left[\mathrm{Ca}^{2+}\right]_{i}$ was significantly higher in rCCN3-stimulated cultures compared with cells treated with DMEM or rRANKL (Figure 6C). However, we did not observe additive or synergistic effects when cells were treated with both rRANKL and rCCN3 (see Supplemental Figure S4 at http://ajp.amjpathol.org).

To determine whether these observed calcium oscillations were important for CCN3-induced osteoclastogenesis of rRANKL-primed RAW 264.7 cells, we incubated cells with a $\mathrm{Ca}^{2+}$ chelator (BAPTA-acetoxymethyl ester) on day 3 before treatment with either DMEM alone or DMEM containing rCCN3 or rRANKL. We determined that treatment with the chelator resulted in $50 \%$ and $25 \%$ decreases in the formation of osteoclasts by rCCN3 and $\mathrm{rRANKL}$, respectively (Figure 7). Taken together, these results indicate that CCN3 is capable of inducing the mobilization of $\left[\mathrm{Ca}^{2+}\right]_{/}$, which plays an important role in promoting CCN3-induced osteoclastogenesis of rRANKL-primed RAW 264.7 cells.
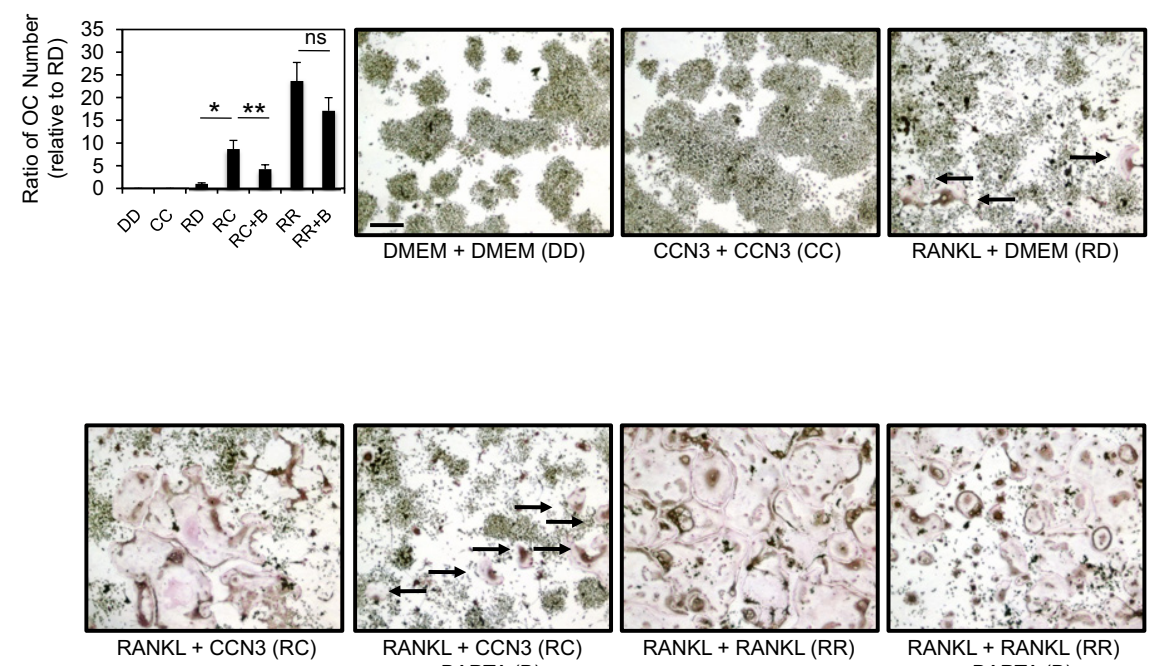

+ BAPTA $(B)$

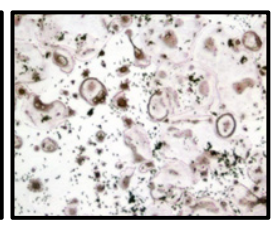

RANKL + RANKL (RR) + BAPTA (B)
Figure 7. $\mathrm{CCN} 3$-mediated induction of osteoclast differentiation of rRANKL-primed monocytes relies on calcium signaling. The number of osteoclasts that differentiated in response to DMEM alone (DD) or human rCCN3 alone (CC) $(600 \mathrm{ng} / \mathrm{mL})$ or after priming with rRANKL and subsequent stimulation with DMEM (RD), human rCCN3 (RC; $600 \mathrm{ng} / \mathrm{mL}$ ), or rRANKL (RR; $50 \mathrm{ng}$ $\mathrm{mL}$ ) is shown in the graph. In addition, rRANKLprimed RAW264.7 cells were pretreated with a calcium chelator (BAPTA) before stimulation with rCCN3 $(\mathrm{RC}+\mathrm{B})$ or rRANKL $(\mathrm{RR}+\mathrm{B})$. Data are from one of two independent experiments, each performed in triplicate. Error bars represent SD. ${ }^{*} P<0.02 ;{ }^{* *} P<0.04$. ns, not signigicant. Representative images of tartrate-resistant alkaline phosphatase-stained RAW 267.4 mouse monocytic cells treated with DMEM alone (DD) or human rCCN3 alone (CC) $(600 \mathrm{ng} / \mathrm{mL})$ or after priming with rRANKL $(50 \mathrm{ng} / \mathrm{mL})$ for 2 days and subsequent stimulation with DMEM (RD), human rCCN3 (RC $600 \mathrm{ng} / \mathrm{mL}$ ), or rRANKL alone (RR; $50 \mathrm{ng} / \mathrm{mL}$ ) or pretreated with BAPTA before stimulation with rCCN3 $(\mathrm{RC}+\mathrm{B})$ or rRANKL $(\mathrm{RR}+\mathrm{B})$. Arrows indicate an osteoclast. Scale bar $=250 \mu \mathrm{m}$. 

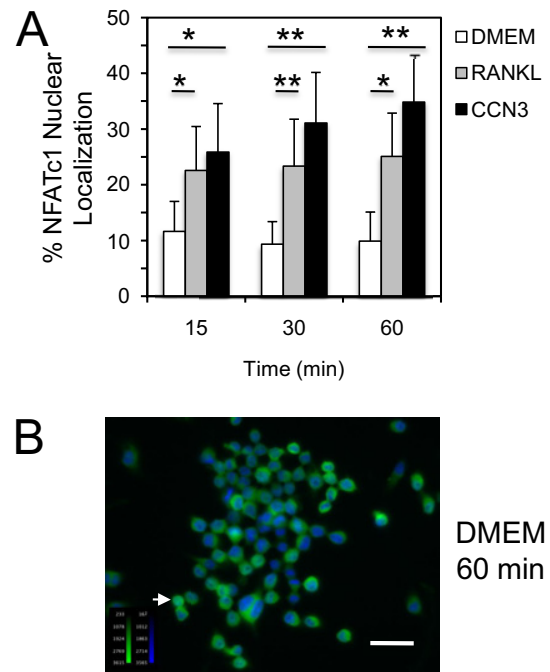

DMEM

$60 \mathrm{~min}$

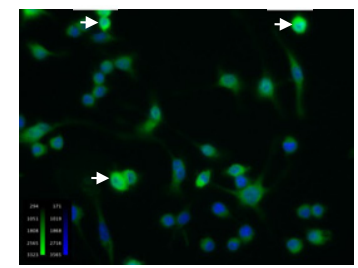

RANKL

$60 \mathrm{~min}$

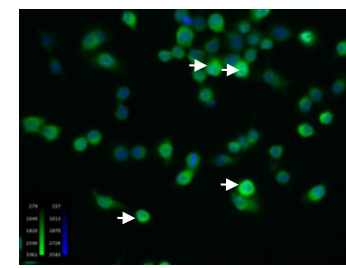

$\mathrm{CCN} 3$

$60 \mathrm{~min}$

Figure 8. CCN3 promotes nfatc1 nuclear localization in RANKL-primed RAW 264.7 cells. A: RAW 264.7 cells were primed with rRANKL $(50 \mathrm{ng} / \mathrm{mL})$ for 48 hours, and then media alone or media containing rRANKL $(50 \mathrm{ng} / \mathrm{mL})$ or rCCN3 $(600 \mathrm{ng} / \mathrm{mL})$ was added for 15,30 , or 60 minutes. Cells were fixed and stained for nfatc1. nfatc1 was visualized by immunofluorescence, and a minimum of four fields per condition were used to determine the percentage of cells exhibiting nuclear nfatc 1 over the total number of cells present in the field. The data represents three independent experiments performed in duplicate, and two observers scored the percentage of cells with nuclear nfatc1 localization. ${ }^{*} P<0.10 ;{ }^{* *} P<0.05$. B: Representatives images of nfatc1 immunofluorescence on the RAW 264.7 cells after 60 minutes of treatment with DMEM only (top), rRANKL $(50 \mathrm{ng} / \mathrm{mL})$ (middle), or rCCN3 $(600 \mathrm{ng} / \mathrm{mL})$ (bottom). White arrows indicate a nuclear localization of nfatc1. Scale bar $=10 \mu \mathrm{m}$ and applies to all panels.

\section{CCN3 Induces Nuclear nfatc1 Localization in rRANKL-Primed RAW 264.7 Cells}

It has been demonstrated that $\mathrm{Ca}^{2+}$ signaling is critical for osteoclast differentiation in part through its ability to induce nuclear localization of nfatc1, a transcription factor important in osteoclastogenesis. ${ }^{49}$ We performed immunofluorescence experiments to determine whether CCN3 could also affect the nuclear translocation of nfatc1. We observed that treatment with rCCN3 $(600 \mathrm{ng} / \mathrm{mL})$, similar to $\mathrm{rRANKL}$ stimulation (50 ng/mL), resulted in a significant increase in the percentage of cells displaying nfatc 1 nuclear localization, which was sustained for at least 60 minutes after stimulation (Figure 8). Moreover, rCCN3-stimulated cultures displayed a higher percentage of cells with nuclear nfatc1 compared with cells treated with rRANKL (Figure 8), which is in agree- ment with the percentage of cells displaying calcium oscillations in response to these stimuli (Figure 6C). Together, these results demonstrate that $\mathrm{rCCN} 3$ can induce nfatc 1 nuclear localization, which is important for osteoclast differentiation.

\section{Signaling through JNK and PKC Is Involved in CCN3-Induced Osteoclast Differentiation}

It has previously been shown that breast cancer-derived factors involve MAPKs and calcium/PKC pathways to form osteoclasts from rRANKL-primed precursors. ${ }^{30}$ Thus, we sought evidence of whether CCN3 played a role in activating these signaling pathways in rRANKL-primed RAW 264.7 cells. We observed that CCN3 treatment resulted in an increase in phosphorylation of JNK and PKC but not p38 (data not shown) or ERK1/2 compared with the control treatment (DMEM) (see Supplemental Figure S5 at http://ajp.amjpathol.org). In fact, CCN3 stimulation resulted in reduced levels of pERK $1 / 2$ compared with DMEM-treated controls. Together, these results argue that CCN3-dependent activation of JNK and PKC signaling pathways may be involved in rCCN3-induced osteoclastogenesis of rRANKL-primed precursors.

\section{Discussion}

Previous studies have examined the relationship between CCN1/Cyr61, CCN2/CTGF, and CCN3/Nov expression and clinical outcome in breast cancer. A positive association exists between high CCN1 expression and larger tumor size, lymph node involvement, and metastasis. ${ }^{50-52}$ Whereas some studies suggest that CCN2/ CTGF is underexpressed in breast tumors relative to normal tissue, ${ }^{51}$ others demonstrate that high CCN2/CTGF levels are critical for the bone metastatic phenotype of breast cancer cells. ${ }^{53,54}$ Several studies have also examined the relationship between CCN3 levels and clinical outcome in patients with breast cancer. One study found no correlation between CCN3 mRNA levels and clinical outcome. ${ }^{52}$ Paradoxically, although high CCN3 expression in breast tumors is associated with good patient outcome, ${ }^{51}$ it also predicts resistance to endocrine therapies and/or cross-resistance in breast tumor samples and cell lines. ${ }^{55}$ Indeed, CCN3 is an estrogen-regulated gene, which may contribute to these contradictory biological outcomes. ${ }^{56}$ The present data extend these observations and demonstrate a role for $\mathrm{CCN} 3$ in promoting breast cancer metastasis to bone.

CCN3 was first identified as a gene overexpressed in myeloblastosis-associated virus-induced nephroblastoma in chickens, giving rise to the designation of Nov for nephroblastoma overexpressed. ${ }^{57}$ CCN3 effects on tumor cell growth are complex and context dependent. Indeed, some studies suggest that CCN3 suppresses breast cancer cell proliferation, ${ }^{33}$ although we do not observe any effect of CCN3 on the proliferation of 66cl4 breast cancer cells in vitro or on mammary tumor outgrowth in the orthotopic site. Thus, CCN3 does not consistently regulate primary tumor cell growth, suggesting that it may elicit varying responses de- 
pending on the cell type and the interacting partners present in these cells. ${ }^{12,58}$

Conversely, additional studies link high CCN3 expression to poor clinical outcomes in prostate ${ }^{20}$ and renal cell carcinomas. ${ }^{58,59}$ These observations are in agreement with a recent study demonstrating that CCN3 increases the metastatic potential of melanoma cells without affecting subcutaneous growth rates. ${ }^{16} \mathrm{CCN} 3$ can impair the proliferation of Ewing's sarcoma cells and diminish their tumorigenicity in vivo while enhancing the migratory and invasive phenotype of Ewing's sarcoma cells. ${ }^{17}$ Moreover, high CCN3 levels are associated with increases in the incidence of metastatic disease in patients with Ewing's sarcoma. ${ }^{18}$ We demonstrate a novel role for CCN3 in the bone microenvironment in facilitating the formation of osteolytic bone metastases. The present results reveal that $\mathrm{CCN} 3$ is expressed in breast cancer cells in bone metastases, which is in agreement with a previous study revealing that $\mathrm{CCN} 3 / \mathrm{Nov}$ is highly expressed in breast cancer bone metastases compared with visceral metastases, such as lung, liver, and brain. ${ }^{60} \mathrm{We}$ demonstrate that CCN3 also enhances breast cancer growth in the bone microenvironment. These data argue that $\mathrm{CCN} 3$ expression may not affect the aggressiveness of breast cancer cells in the primary site but may play a role in the ability of breast cancer cells to grow in the bone microenvironment.

Tumor cells must interact with cells present in the metastatic microenvironment to grow and survive in a distant site. Bone is composed of two main types of cells, osteoblasts and osteoclasts, which are responsible for bone formation and resorption, respectively. The coordinated differentiation of these cell types is critical to maintain normal bone turnover and tissue homeostasis. However, the arrival of tumor cells in the bone microenvironment can disrupt this interplay and tip the balance to a resorptive state. This creates a vicious cycle whereby factors released from the bone microenvironment through osteoclastmediated bone resorption can promote tumor cell growth, which further potentiates bone destruction. ${ }^{3}$ Two proteins, RANKL and OPG, are critical for maintaining the coordinated action of osteoblasts and osteoclasts. RANKL induces osteoclastogenesis and is expressed by osteoblast precursors, whereas OPG is a soluble decoy receptor that binds and neutralizes RANKL. ${ }^{42,43}$ We demonstrate that CCN3 can impair osteoblast differentiation in a primary culture of bone marrow cells. In doing so, CCN3 alters the RANKL/OPG ratio to favor increased concentrations of RANKL and lower concentrations of OPG, a soluble decoy receptor for RANKL. This observation is in agreement with published results demonstrating that rCCN3 can impair osteoblast differentiation of established cell models by interacting directly with and activating Notch, a known inhibitor of osteoblast differentiation. ${ }^{38,61}$ The C-terminal domain of CCN3 has been implicated in the activation of Notch signaling. The CCN3 C-terminal domain induces transcription of hey 1 and hes1, two downstream targets of the cleaved Notch intracellular domain, whereas a mutant CCN3 protein lacking this domain (Ccn3delCT) fails to induce these targets. ${ }^{38}$ However, we performed immunofluorescence on rCCN3-treated primary culture of bone marrow cells and did not observe significant nuclear translocation of the Notch intracellular domain or induction of Hes 1 or Hey1 transcripts (data not shown). Furthermore, CCN3 can also interact with and antagonizes bone morphogenetic protein 2 signaling, which can also lead to the inhibition of osteoblast differentiation. ${ }^{38-40,61,62}$

The importance of $\mathrm{CCN} 3$ in regulating bone formation has also been revealed through the characterization of transgenic mouse models. Overexpression of CCN3, driven by the osteocalcin promoter, resulted in a decrease in bone formation in one transgenic line and osteopenia, secondary to an increase in bone resorption, in a second transgenic line. ${ }^{40}$ The present results are in agreement with these observations and suggest that breast cancer cells can subvert the normal role played by CCN3 to favor bone destruction that characterizes osteolytic breast cancer bone metastases. In another transgenic mouse model, targeting of the third exon encoding the von Willebrand factor type $\mathrm{C}$ domain ( $\mathrm{NOV}^{\text {de/3-/-}}{ }^{-}$) resulted in mice that did not express full-length CCN3 and displayed very low levels of a CCN3 protein lacking the von Willebrand factor type $\mathrm{C}$ domain. These mice displayed numerous phenotypes, including enlarged vertebrae, elongated long bones/digits, and a delay in ossification. ${ }^{37}$

Another novel finding in the present study was the demonstration that rCCN3 can support osteoclast differentiation of rRANKL-primed, but not naive, osteoclast precursors. This observation is interesting in light of the results demonstrating that $\mathrm{rCCN} 3$ impairs osteoblast differentiation, leading to elevated levels of RANKL and decreased OPG expression. Thus, breast cancer cells that express high levels of CCN3 would be equipped to alter the functions of osteoblasts and osteoclasts to favor bone destruction. Indeed, most breast cancer bone metastases that we analyzed demonstrated strong CCN3 staining in the tumor epithelium or stroma. The present observations, coupled with published data suggesting that $\mathrm{CCN} 3 / \mathrm{NOV}$ is highly expressed specifically in bone metastases, ${ }^{60}$ suggest that $C C N 3$ expression may be up-regulated once breast tumor cells reach the bone.

The present results suggest that CCN3 promotes osteoclast differentiation of rRANKL-primed precursors through its ability to induce calcium oscillations and subsequent nfatc1 nuclear localization. A role for CCN3 in calcium signaling has not been extensively studied; however, previous studies have shown that CCN3 can induce calcium mobilization in different cell types. ${ }^{47,48}$ In the osteoclast precursor, nuclear localization of the transcription factor nfatc1 is essential for the expression of tartrate-resistant acid phosphatase, calcitonin receptor, cathepsin $\mathrm{K}$, and $\beta 3$ integrin, which leads to osteoclastogenesis. ${ }^{49,63-65}$ RANKL contributes to the expression of nfatc $1^{63,65}$ and allows nfatc 1 to undergo autoamplification after a positive feedback regulation. ${ }^{66}$ We demonstrate that $\mathrm{rCCN} 3$, in rRANKL-primed cells, can induce calcium mobilization to a greater degree compared with rRANKL itself, resulting in the robust nuclear translocation of nfatc1. These observations are interesting in light of the results indicating that rCCN3-mediated effects on osteoclast differentiation seem to be more sensitive to a calcium chelator com- 
pared with rRANKL stimulation. These data extend previous studies implicating CCN3 in the control of calcium mobilization and is the first to demonstrate such a role in osteoclast differentiation.

The present results argue that CCN3-mediated effects on osteoclast differentiation may be influenced by its ability to activate JNK and PKC $\alpha / \beta$ phosphorylation. Moreover, CCN3 stimulation reduced pERK1/2 levels while having no effect on p38 phosphorylation (data not shown). We previously demonstrated that soluble factors secreted from human breast cancers favor osteoclastogenesis of rRANKL-primed monocytes by inducing calcium oscillations in these cells. In these studies, activation of the p38, ERK, and PKC pathways were observed after treatment with conditioned media from breast cancer cells. ${ }^{30,32}$ Thus, CCN3 seems to engage different signaling pathways to promote osteoclastogenesis of rRANKL-primed precursors. The present results are consistent with previous observations indicating that $\mathrm{CCN} 3$ can impair ERK phosphorylation in chronic myeloid leukemia. ${ }^{67}$ Moreover, CCN3 has recently been shown to differentially rely on JNK or p38 signaling in astrocytes, which is believed to be dictated by the particular integrin receptors engaged by CCN3. ${ }^{68}$

We revealed a functional role for $\mathrm{CCN} 3$ in promoting breast cancer metastasis to bone. This effect is likely to stem from the ability of CCN3 to impair osteoblast differentiation while simultaneously promoting osteoclastogenesis from rRANKL-primed precursors. In this way, CCN3 influences both of the main cell types in bone to create a pro-resorptive environment characteristic of osteolytic breast cancer bone metastases.

\section{Acknowledgments}

We thank the McGill Centre for Bone and Periodontal Research and the Goodman Cancer Research Centre for routine histologic services, Dr. Josie Ursini-Siegel and members of the Siegel Laboratory for their thoughtful discussions and critical reading of the manuscript, and Dr. Damien Le Nihouannen for his technical help and advice.

\section{References}

1. Coleman RE: Skeletal complications of malignancy. Cancer 1997, 80:1588-1594

2. Hess KR, Varadhachary GR, Taylor SH, Wei W, Raber MN, Lenzi R, Abbruzzese JL: Metastatic patterns in adenocarcinoma. Cancer 2006, 106:1624-1633

3. Mundy GR: Metastasis to bone: causes, consequences and therapeutic opportunities. Nat Rev Cancer 2002, 2:584-593

4. Costa L, Major PP: Effect of bisphosphonates on pain and quality of life in patients with bone metastases. Nat Clin Pract Oncol 2009, 6:163-174

5. Neville-Webbe HL, Coleman RE: Bisphosphonates and RANK ligand inhibitors for the treatment and prevention of metastatic bone disease. Eur J Cancer 2010, 46:1211-1222

6. Rose AA, Siegel PM: Emerging therapeutic targets in breast cancer bone metastasis. Future Oncol 2010, 6:55-74

7. Brigstock DR, Goldschmeding R, Katsube KI, Lam SC, Lau LF, Lyons K, Naus C, Perbal B, Riser B, Takigawa M, Yeger H: Proposal for a unified CCN nomenclature. Mol Pathol 2003, 56:127-128
8. Perbal B: $C C N$ proteins: multifunctional signalling regulators. Lancet 2004, 363:62-64

9. Pennica D, Swanson TA, Welsh JW, Roy MA, Lawrence DA, Lee J, Brush J, Taneyhill LA, Deuel B, Lew M, Watanabe C, Cohen RL, Melhem MF, Finley GG, Quirke P, Goddard AD, Hillan KJ, Gurney AL, Botstein D, Levine AJ: WISP genes are members of the connective tissue growth factor family that are up-regulated in wnt-1-transformed cells and aberrantly expressed in human colon tumors. Proc Natl Acad Sci U S A 1998, 95:14717-14722

10. Brigstock DR: The CCN family: a new stimulus package. J Endocrinol 2003, 178:169-175

11. Leask A, Abraham DJ: All in the CCN family: essential matricellular signaling modulators emerge from the bunker. J Cell Sci 2006, 119: 4803-4810

12. Zuo GW, Kohls CD, He BC, Chen L, Zhang W, Shi Q, Zhang BQ, Kang Q, Luo J, Luo X, Wagner ER, Kim SH, Restegar F, Haydon RC, Deng ZL, Luu HH, He TC, Luo Q: The CCN proteins: important signaling mediators in stem cell differentiation and tumorigenesis. Histol Histopathol 2010, 25:795-806

13. Fu CT, Bechberger JF, Ozog MA, Perbal B, Naus CC: CCN3 (NOV) interacts with connexin43 in $\mathrm{C} 6$ glioma cells: possible mechanism of connexin-mediated growth suppression. J Biol Chem 2004, 279: 36943-36950

14. Fukunaga-Kalabis M, Martinez G, Telson SM, Liu ZJ, Balint K, Juhasz I, Elder DE, Perbal B, Herlyn M: Downregulation of CCN3 expression as a potential mechanism for melanoma progression. Oncogene 2008, 27:2552-2560

15. Gupta N, Wang H, McLeod TL, Naus CC, Kyurkchiev S, Advani S, Yu J, Perbal B, Weichselbaum RR: Inhibition of glioma cell growth and tumorigenic potential by CCN3 (NOV). Mol Pathol 2001, 54:293-299

16. Vallacchi V, Daniotti M, Ratti F, Di Stasi D, Deho P, De Filippo A, Tragni G, Balsari A, Carbone A, Rivoltini L, Parmiani G, Lazar N, Perbal B, Rodolfo M: CCN3/nephroblastoma overexpressed matricellular protein regulates integrin expression, adhesion, and dissemination in melanoma. Cancer Res 2008, 68:715-723

17. Benini S, Perbal B, Zambelli D, Colombo MP, Manara MC, Serra M, Parenza M, Martinez V, Picci P, Scotlandi K: In Ewing's sarcoma CCN3(NOV) inhibits proliferation while promoting migration and invasion of the same cell type. Oncogene 2005, 24:4349-4361

18. Manara MC, Perbal B, Benini S, Strammiello R, Cerisano V, Perdichizzi S, Serra M, Astolfi A, Bertoni F, Alami J, Yeger H, Picci P, Scotlandi K: The expression of ccn3(nov) gene in musculoskeletal tumors. Am J Pathol 2002, 160:849-859

19. Perbal B, Lazar N, Zambelli D, Lopez-Guerrero JA, Llombart-Bosch A, Scotlandi K, Picci P: Prognostic relevance of CCN3 in Ewing sarcoma. Hum Pathol 2009, 40:1479-1486

20. Maillard M, Cadot B, Ball RY, Sethia K, Edwards DR, Perbal B, Tatoud R: Differential expression of the ccn3 (nov) proto-oncogene in human prostate cell lines and tissues. Mol Pathol 2001, 54:275-280

21. Perbal B, Zuntini M, Zambelli D, Serra M, Sciandra M, Cantiani L, Lucarelli E, Picci P, Scotlandi K: Prognostic value of CCN3 in osteosarcoma. Clin Cancer Res 2008, 14:701-709

22. Rose AA, Pepin F, Russo C, Abou Khalil JE, Hallett M, Siegel PM: Osteoactivin promotes breast cancer metastasis to bone. Mol Cancer Res 2007, 5:1001-1014

23. Rose AA, Grosset AA, Dong Z, Russo C, Macdonald PA, Bertos NR, St-Pierre Y, Simantov R, Hallett M, Park M, Gaboury L, Siegel PM: Glycoprotein nonmetastatic $B$ is an independent prognostic indicator of recurrence and a novel therapeutic target in breast cancer. Clin Cancer Res 2010, 16:2147-2156

24. Chevalier G, Yeger H, Martinerie C, Laurent M, Alami J, Schofield PN, Perbal B: novH: differential expression in developing kidney and Wilm's tumors. Am J Pathol 1998, 152:1563-1575

25. Pfaffl MW: A new mathematical model for relative quantification in real-time RT-PCR. Nucleic Acids Res 2001, 29:e45

26. Northey JJ, Chmielecki J, Ngan E, Russo C, Annis MG, Muller WJ, Siegel PM: Signaling through ShcA is required for transforming growth factor $\beta$ - and Neu/ErbB-2-induced breast cancer cell motility and invasion. Mol Cell Biol 2008, 28:3162-3176

27. Pasmant E, Ortonne N, Rittie L, Laurendeau I, Levy P, Lazar V, Parfait B, Leroy K, Dessen P, Valeyrie-Allanore L, Perbal B, Wolkenstein P, Vidaud $M$, Vidaud D, Bieche I: Differential expression of $\mathrm{CCN} 1 /$ CYR61. CCN3/NOV, CCN4/WISP1, and CCN5/WISP2 in neurofibro- 
matosis type 1 tumorigenesis, J Neuropathol Exp Neurol 2010, 69:60-69

28. Perbal B, Martinerie C, Sainson R, Werner M, He B, Roizman B: The C-terminal domain of the regulatory protein $\mathrm{NOVH}$ is sufficient to promote interaction with fibulin 1C: a clue for a role of NOVH in cell-adhesion signaling. Proc Natl Acad Sci U S A 1999, 96:869-874

29. Armstrong S, Pereverzev A, Dixon SJ, Sims SM: Activation of P2X7 receptors causes isoform-specific translocation of protein kinase $\mathrm{C}$ in osteoclasts. J Cell Sci 2009, 122:136-44

30. Tiedemann K, Hussein O, Sadvakassova G, Guo Y, Siegel PM, Komarova SV: Breast cancer-derived factors stimulate osteoclastogenesis through the $\mathrm{Ca}^{2+}$ /protein kinase $\mathrm{C}$ and transforming growth factor- $\beta$ / MAPK signaling pathways. J Biol Chem 2009, 284:33662-33670

31. Komarova SV, Pilkington MF, Weidema AF, Dixon SJ, Sims SM: RANK ligand-induced elevation of cytosolic $\mathrm{Ca}^{2+}$ accelerates nuclear translocation of nuclear factor $\kappa \mathrm{B}$ in osteoclasts. J Biol Chem 2003, 278: $8286-8293$

32. Guo Y, Tiedemann K, Khalil JA, Russo C, Siegel PM, Komarova SV: Osteoclast precursors acquire sensitivity to breast cancer derived factors early in differentiation. Bone 2008, 43:386-393

33. Sin WC, Tse M, Planque N, Perbal B, Lampe PD, Naus CC: MatricelIular protein CCN3 (NOV) regulates actin cytoskeleton reorganization. J Biol Chem 2009, 284:29935-29944

34. Aslakson CJ, Miller FR: Selective events in the metastatic process defined by analysis of the sequential dissemination of subpopulations of a mouse mammary tumor. Cancer Res 1992, 52:1399-1405

35. Eckhardt BL, Parker BS, van Laar RK, Restall CM, Natoli AL, Tavaria MD, Stanley KL, Sloan EK, Moseley JM, Anderson RL: Genomic analysis of a spontaneous model of breast cancer metastasis to bone reveals a role for the extracellular matrix. Mol Cancer Res 2005, $3: 1-13$

36. Casimiro S, Guise TA, Chirgwin J: The critical role of the bone microenvironment in cancer metastases. Mol Cell Endocrinol 2009, 310:71-81

37. Heath E, Tahri D, Andermarcher E, Schofield P, Fleming S, Boulter CA: Abnormal skeletal and cardiac development, cardiomyopathy, muscle atrophy and cataracts in mice with a targeted disruption of the Nov (Ccn3) gene. BMC Dev Biol 2008, 8:18

38. Katsuki Y, Sakamoto K, Minamizato T, Makino H, Umezawa A, Ikeda MA, Perbal B, Amagasa T, Yamaguchi A, Katsube K: Inhibitory effect of $\mathrm{CT}$ domain of $\mathrm{CCN} 3 / \mathrm{NOV}$ on proliferation and differentiation of osteogenic mesenchymal stem cells, Kusa-A1. Biochem Biophys Res Commun 2008, 368:808-814

39. Minamizato T, Sakamoto K, Liu T, Kokubo H, Katsube K, Perbal B, Nakamura S, Yamaguchi A: CCN3/NOV inhibits BMP-2-induced osteoblast differentiation by interacting with BMP and Notch signaling pathways. Biochem Biophys Res Commun 2007, 354:567-573

40. Rydziel S, Stadmeyer L, Zanotti S, Durant D, Smerdel-Ramoya A, Canalis E: Nephroblastoma overexpressed (Nov) inhibits osteoblastogenesis and causes osteopenia. J Biol Chem 2007, 282:1976219772

41. Dougall WC, Chaisson M: The RANK/RANKL/OPG triad in cancerinduced bone diseases. Cancer Metastasis Rev 2006, 25:541-549

42. Khosla S: Minireview: the OPG/RANKL/RANK system. Endocrinology 2001, 142:5050-5055

43. Ooi LL, Zheng Y, Stalgis-Bilinski K, Dunstan CR: The bone remodeling environment is a factor in breast cancer bone metastasis. Bone 201148:66-70

44. Gori F, Hofbauer LC, Dunstan CR, Spelsberg TC, Khosla S, Riggs BL: The expression of osteoprotegerin and RANK ligand and the support of osteoclast formation by stromal-osteoblast lineage cells is developmentally regulated. Endocrinology 2000, 141:4768-4776

45. Hsu H, Lacey DL, Dunstan CR, Solovyev I, Colombero A, Timms E, Tan HL, Elliott G, Kelley MJ, Sarosi I, Wang L, Xia XZ, Elliott R, Chiu L, Black T, Scully S, Capparelli C, Morony S, Shimamoto G, Bass MB, Boyle WJ: Tumor necrosis factor receptor family member RANK mediates osteoclast differentiation and activation induced by osteoprotegerin ligand. Proc Natl Acad Sci U S A 1999, 96:3540-3545

46. Islam S, Hassan F, Tumurkhuu G, Dagvadorj J, Koide N, Naiki Y, Yoshida T, Yokochi T: Receptor activator of nuclear factor- $\kappa$ B ligand induces osteoclast formation in RAW 264.7 macrophage cells via augmented production of macrophage-colony-stimulating factor. Microbiol Immunol 2008, 52:585-590
47. Li CL, Martinez V, He B, Lombet A, Perbal B: A role for CCN3 (NOV) in calcium signalling. Mol Pathol 2002, 55:250-261

48. Lombet A, Planque N, Bleau AM, Li CL, Perbal B: CCN3 and calcium signaling. Cell Commun Signal 2003, 1:1

49. Negishi-Koga T, Takayanagi $\mathrm{H}: \mathrm{Ca}^{2+}{ }_{-N F A T c 1}$ signaling is an essential axis of osteoclast differentiation. Immunol Rev 2009, 231:241-256

50. Dhar A, Ray A: The CCN family proteins in carcinogenesis. Exp Oncol 2010, 32:2-9

51. Jiang WG, Watkins G, Fodstad O, Douglas-Jones A, Mokbel K, Mansel RE: Differential expression of the CCN family members Cyr61, CTGF and Nov in human breast cancer. Endocr Relat Cancer 2004, 11:781-791

52. Xie D, Miller CW, O'Kelly J, Nakachi K, Sakashita A, Said JW, Gornbein J, Koeffler HP: Breast cancer: Cyr61 is overexpressed, estrogeninducible, and associated with more advanced disease. J Biol Chem 2001, 276:14187-14194

53. Kang Y, Siegel PM, Shu W, Drobnjak M, Kakonen SM, Cordon-Cardo C, Guise TA, Massague J: A multigenic program mediating breast cancer metastasis to bone. Cancer Cell 2003, 3:537-549

54. Shimo T, Kubota S, Yoshioka N, Ibaragi S, Isowa S, Eguchi T, Sasaki A, Takigawa M: Pathogenic role of connective tissue growth factor (CTGF/CCN2) in osteolytic metastasis of breast cancer. J Bone Miner Res 2006, 21:1045-1059

55. Ghayad SE, Vendrell JA, Bieche I, Spyratos F, Dumontet C, Treilleux I, Lidereau R, Cohen PA: Identification of TACC1, NOV, and PTTG1 as new candidate genes associated with endocrine therapy resistance in breast cancer. J Mol Endocrinol 2009, 42:87-103

56. Vendrell JA, Magnino F, Danis E, Duchesne MJ, Pinloche S, Pons M, Birnbaum D, Nguyen C, Theillet C, Cohen PA: Estrogen regulation in human breast cancer cells of new downstream gene targets involved in estrogen metabolism, cell proliferation and cell transformation. $J$ Mol Endocrinol 2004, 32:397-414

57. Joliot V, Martinerie C, Dambrine G, Plassiart G, Brisac M, Crochet J, Perbal B: Proviral rearrangements and overexpression of a new cellular gene (nov) in myeloblastosis-associated virus type 1-induced nephroblastomas. Mol Cell Biol 1992, 12:10-21

58. Planque N, Perbal B: A structural approach to the role of CCN (CYR61/ CTGF/NOV) proteins in tumourigenesis. Cancer Cell Int 2003, 3:15

59. Glukhova L, Angevin E, Lavialle C, Cadot B, Terrier-Lacombe MJ, Perbal B, Bernheim A, Goguel AF: Patterns of specific genomic alterations associated with poor prognosis in high-grade renal cell carcinomas. Cancer Genet Cytogenet 2001, 130:105-110

60. Zhang XH, Wang Q, Gerald W, Hudis CA, Norton L, Smid M, Foekens $\mathrm{JA}$, Massague $\mathrm{J}$ : Latent bone metastasis in breast cancer tied to Src-dependent survival signals. Cancer Cell 2009, 16:67-78

61. Katsube K, Ichikawa S, Katsuki Y, Kihara T, Terai M, Lau LF, Tamamura Y, Takeda S, Umezawa A, Sakamoto K, Yamaguchi A: CCN3 and bone marrow cells. J Cell Commun Signal 2009, 3:135-145

62. Canalis E: Nephroblastoma overexpressed (Nov) is a novel bone morphogenetic protein antagonist. Ann N Y Acad Sci 2007, 1116:50-58

63. Hirotani H, Tuohy NA, Woo JT, Stern PH, Clipstone NA: The calcineurin/nuclear factor of activated $T$ cells signaling pathway regulates osteoclastogenesis in RAW264.7 cells. J Biol Chem 2004, 279: 13984-13992

64. Ishida N, Hayashi K, Hoshijima M, Ogawa T, Koga S, Miyatake Y, Kumegawa M, Kimura T, Takeya T: Large scale gene expression analysis of osteoclastogenesis in vitro and elucidation of NFAT2 as a key regulator. J Biol Chem 2002, 277:41147-41156

65. Takayanagi $H$, Kim S, Koga T, Nishina H, Isshiki M, Yoshida H, Saiura A, Isobe M, Yokochi T, Inoue J, Wagner EF, Mak TW, Kodama T, Taniguchi $\mathrm{T}$ : Induction and activation of the transcription factor NFATc1 (NFAT2) integrate RANKL signaling in terminal differentiation of osteoclasts. Dev Cell 2002, 3:889-901

66. Asagiri M, Sato K, Usami T, Ochi S, Nishina H, Yoshida H, Morita I, Wagner EF, Mak TW, Serfling E, Takayanagi H: Autoamplification of NFATc1 expression determines its essential role in bone homeostasis. J Exp Med 2005, 202:1261-1269

67. McCallum L, Lu W, Price S, Lazar N, Perbal B, Irvine AE: CCN3: a key growth regulator in Chronic Myeloid Leukaemia. J Cell Commun Signal 2009, 3:115-124

68. Le Dreau G, Kular L, Nicot AB, Calmel C, Melik-Parsadaniantz S, Kitabgi P, Laurent M, Martinerie C: NOV/CCN3 upregulates CCL2 and CXCL1 expression in astrocytes through $\beta 1$ and $\beta 5$ integrins. Glia 2010, 58:1510-1521 